мятников истории и культуры : официальный сайт. - URL: http://voopik.ru/istorikoetnograficheskyfest.php?bitrix_include_areas=Y\&bitrix_show_mode=edit\&clear_cache=Y (дата обращения: 20.04.2019).

5. Визит Орёл : официальный туристический портал Орловской области : [сайт]. - Орёл : Центр кластерного развития Орловской области, 2017- . URL: http://visit-orel.ru/ (дата обращения: 20.04.2019). - Текст : электронный.

Stanislav N. Abakumov, Ph. D. in History, Associate Professor All-Russian Society for the Preservation of Historical and Cultural Monuments, Oryol Oblast Branch (Oryol, Russia) abakumovstn@gmail.com

Viktoria A. Abakumova Moscow State Institute of Culture (Moscow, Russia) touristica@inbox.ru

\title{
TOURISTIC CLUSTER IN ORYOL OBLAST, RUSSIA, AS A TOOL FOR INCLUSION OF OBJECTS OF CULTURAL HERITAGE INTO SPHERE OF TOURISM
}

Abstract. The article gives the authors' assessment of contribution that touristic clusters make to popularization of objects of cultural heritage located in regions of the today's Russian Federation (a case of Oryol Oblast, Central Federal District). On the authors' conclusion, incorporation of marketing strategies in promoting various Russian areas with significant touristic potential in domestic market of touristic resources helped to find new methods and technologies for integration of objects of cultural heritage into a system of touristic resources of Russia. Also, the paper describes a useful experience in building touristic clusters in Oryol Oblast that is fit for spreading in various regions of the Russian Federation.

Keywords: touristic cluster, governmental funding for touristic clusters, small and medium-sized businesses in touristic sphere, touristic territories, culture, tourism, event-tourism, strategies of touristic clusters development, a product in tourism sphere, cultural heritage of a region.

УДК $7(571.53 / .55)[=512.1+512.3+16]$

DOI: $10.32340 / 2414-9101-2019-2-10-15$

Н. Б. Дашиева, доктор исторических наук, профессор Восточно-Сибирский государственный институт культуры (Улан-Удэ, Россия) dashieva-n@yandex.ru

\section{СОХРАНЕНИЕ И РАЗВИТИЕ ТРАДИЦИОННОЙ ХУДОЖЕСТВЕННОЙ КУЛЬТУРЫ НАРОДОВ ЮЖНОЙ И ВОСТОЧНОЙ СИБИРИ (КОНЦЕПЦИЯ ПРОЕКТА)}

Аннотация. Сохранение ценностно-смыслового единства системы традиционной художественной культуры этнических сообществ и укрепление её способности к самостоятельному развитию - ключевые условия воспроизводства культурного многообразия в мировом, общероссийском и региональном масштабах. Автор излагает собственный вариант концепции сохранения и развития традиционной художественной культуры тюркских, монгольских и славянских этносов, населяющих сельские территории современной Южной и Восточной Сибири. Активная популяризация образцов народной художественной культуры в сетевых межкультурных пространствах рассматривается автором в качестве ценного ресурса социального и экономического роста наименее развитых в хозяйственном и инфраструктурном отношении провинциальных территорий азиатской части современной России.

Ключевые слова: традиционная художественная культура, народная художественная культуpa, полиэтничный российский регион, проблемы сохранение традиционной художественной культуpbl, художественно-культурный заповедник, тюркские народы, монгольские народы, славянские народы, алтайцьи, тувинцы, тофалары, эвенки, русские. 


\section{1. Целесообразность проекта}

Анализ современных цивилизационных процессов показывает, что одним из доминирующих принципов познания многообразия и единства социально-культурной и духовной жизни человека становится принцип различия. Именно сравнительный анализ, направленный на изучение многообразия как целого, определяет методологическую основу трансляции культурного наследия человечества как диалога цивилизаций, как диалога культур [1].

В условиях расширяющейся в мире глобализации, урбанизации и стандартизации жизни важную роль в сохранении культурного многообразия мира выполняет традиционная художественная культура. В своей базовой основе традиционная художественная культура выражается в устных традициях, исполнительском искусстве, обрядах, празднествах, декоративно-прикладном искусстве, реализующихся в контексте социокультурной, этнической, межэтнической и экономической систем. Деятельность хранителей и носителей этой традиции непрерывно порождает продукты художественного и духовного производства - музыка, поэзия, танец, игра и др., а также продукты материального производства - народный костюм, музыкальные инструменты, художественно оформленные предметы быта, орудия труда, народная архитектура и другие жанры прикладного искусства [2;3].

Традиционная художественная культура представляет собой особого рода синкретическую и синтетическую культуру бесписьменной традиции, её целостность и способность к развитию обеспечивает целость и способность к выживанию этнических сообществ. Поэтому сегодня традиционная художественная культура даже небольших этносоциальных образований должна рассматриваться в контексте сохранения культурного разнообразия мирового сообщества.

В нашей современности традиционная художественная культура всех народов неуклонно разрушается, деградирует, исчезает, вытесняется культурой письменной традиции и сохраняется лишь в местах мало затронутых этими процессами, с моноэтничным населением, в сельских районах с неразвитой коммуникационной инфраструктурой. Таким образом, традиционная художественная культура сохраняется лишь на периферии культурных процессов, а в общественном сознании формируется представление о ней как культуре «отсталого» в культурном развитии населения.

Значительную роль в решении этих проблем играет: а) формирование в общественном сознании понимания традиционной художественной культуры народов мира как общечеловеческого достояния, являющегося своеобразной квинтэссенцией древнейшего опыта сосуществования людей в разных историко-этнических условиях, опыта адаптации людей к разной природно-климатической среде, исторически сложившейся спецификой мировоззрения и мировосприятия; б) укрепление доступа к традиционной художественной культуре разных народов, в сфере которой особенно ярко реализуется этническая специфика культуры, продвижение сотрудничества, обмен и распространение ее продуктами между народами. Одним из эффективных способов решения данной проблемы может стать сохранение и распространение посредством создания и включения в сетевые межкультурные пространства лучших образцов традиционной художественной культуры разных народов мира, для лучшего доступа к ней специалистов, детей и молодёжи, туристов и широкого круга пользователей в разных странах мира.

Негативные воздействия на традиционную художественную культуру усиливаются по мере расширения миграционных процессов сельского населения в города под воздействием безработицы. Городская культура, как правило, полиэтнична, её жизнь формируется под влиянием средств массовой информации, где ведущую роль играет мировая массовая культура. Все это, естественно, ведет к деградации и этнической обезличенности традиционной художественной культуры.

Решение этой проблемы связано с актуализацией фактора традиционной художественной культуры как ресурса развития, активизации жизнеспособных художественно-культурных традиций, способных дать социальный и экономический эффект для устойчивого развития наименее развитых территорий, сельского населения, групп и лиц, являющихся хранителями и носителями традиционной художественной культуры в разных странах и регионах. Мы выделили четыре уровня общих проблем нашей современности в области традиционной художественной культуры, которые имеют последовательную связь между собой:

- сохранение культурного многообразия мирового сообщества;

- сохранение целостности социокультурного пространства стран и регионов; 
- преодоление размывания и утраты у подрастающих поколений культурной и этнической идентификации;

- создание условий для устойчивого социального и экономического развития сельского населения, обеспечение материальной и моральной поддержки хранителей и носителей традиционной художественной культуры.

Конкретные проблемы данного проекта. На территории регионов Южной и Восточной Сибири расположены национальные Республики Алтай, Тыва, Алтайский край и Иркутская область, входящие в Сибирский федеральный округ, Республика Бурятия и Забайкальский край, входящие в состав Дальневосточного федерального округа Российской Федерации. Исторически эти регионы представляли собой территории, где с глубокой древности происходили миграции тюркских, монгольских и тунгусо-маньчжурских, в период энеолита - раннего железного века - индоевропейских этнических групп, а начиная с XVI века - отдельных групп русского этноса. Несмотря на языковые и комплексные хозяйственно-культурные различия, традиционная культура коренных народов южно- и восточно-сибирского регионов характеризуется общими компонентами или комплексами компонентов, свидетельствующих об этногенетических или их тесных этнокультурных взаимодействиях в далёком или исторически обозримом прошлом. Именно эти элементы определяют регионы Южной и Восточной Сибири как некую историко-культурную целостность и обуславливают территориальные границы проекта.

В настоящее время в Южной и Восточной Сибири проживают народы нескольких языковых групп: тюркской - алтайцы, тувинцы, тофалары, монгольской - буряты, тунгусо-маньчжурской эвенки, а также славянской - русские. Таким образом, Южная и Восточная Сибирь представляют собой уникальные по своему историко-культурному наследию регионы России, где до наших дней сохранилось многообразие языков, этнической специфики во всех сферах культуры, в том числе и многообразие типов и форм художественной культуры. Проблема состоит в необходимости:

- организации комплексного обследования традиционной художественной культуры народов Южной и Восточной Сибири;

- проведения на научной основе обработки и анализа материалов обследования;

- введения лучших образцов в мировое информационное пространство;

- выработки комплекса мероприятий по решению проблемы сохранения традиционной художественной культуры народов Южной и Восточной Сибири, скоординированной по задачам, ресурсам и срокам на региональных и межрегиональных уровнях;

- разработки на научной основе рекомендаций для соответствующих местных и региональных государственных структур в составлении долгосрочных Концепций культурной политики в регионах.

\section{Целевые (плановые) группы и лица, которым осуществление проекта принесёт пользу}

Проект окажет моральную, материальную и организационную поддержку индивидуальным исполнителям разных жанров фольклора, народным мастерам, производящим продукты традиционного художественного творчества, фольклорно-этнографическим коллективам, гражданам, являющихся хранителями и носителями традиционной художественной культуры, национальным общественным объединениям - национально-культурным автономиям, этнокультурным центрам, расположенным в регионе Южной и Восточной Сибири.

От участия в её реализации получат опыт в проектной работе межрегионального характера преподаватели, аспиранты и студенты высших и средних специальных учебных заведений, деятели науки, искусства, работники сферы культуры и образования из регионов Южной и Восточной Сибири.

Россия является одной из самых многонациональных и поликультурных стран мира. Для России проблема сохранения традиционной художественной культуры народов, населяющих ее, становится одной из важных государственных задач, имеющих комплексный и масштабный характер. В настоящее время в решении этой проблемы преобладает эпизодичность и локальность. Сохраняя традиционную художественную культуру отдельных народов, мы сохраняем не только культурную самобытность отдельных этносов, но и культурное разнообразие региона, страны. Реализация проекта позволит повысить конкурентную способность хранителей, исполнителей и носителей 
традиционной художественной культуры целой группы коренных народов России, проживающих в регионе Южной и Восточной Сибири, а также русского старожильческого населения Сибири старообрядцев и казаков.

Учитывая, что культурно-познавательные мотивации в настоящее время являются ведущими в структуре туристских поездок, для Республики Бурятия и Иркутской области проект имеет особое значение, так как на их территории, на побережье озера Байкал реализуются долгосрочные федеральные проекты организации двух туристско-рекреационных особых экономических зон.

Проект «Сохранение и развитие традиционной художественной культуры народов Южной и Восточной Сибири», обеспечивающий комплексный подход к решению соответствующей проблемы, предусматривает:

- реализацию системы защитных мер, направленных на преодоление негативных факторов и неблагоприятных последствий процессов глобализации, влияющих на традиционную художественную культуру;

- реализацию системы перспективных мер, закладывающих основы долговременного устойчивого культурного развития регионов в современных неблагоприятных для традиционной художественной культуры социально-экономических условиях;

- реализацию мер, укрепляющих потенциал традиционной художественной культуры субъектов через создание сетей.

\section{2. Описание проекта и его эффективность}

Общая цель проекта - сохранение традиционной художественной культуры народов Южной и Восточной Сибири и обеспечение доступа к ней граждан других регионов и других стран. Традиционная художественная культура будет рассматриваться не как абстрактное благо, но и как услуга, адресованная конкретному потребителю, поэтому главная миссия проекта - повышение ее качества, доступности, создание сети.

Важным фактором, способствующим решению этих проблем, становится объединение и координирование сил со стороны научных, образовательных учреждений регионов, населения, общественных объединений, инициативных групп и т. д. Путь комплексного объединения всех заинтересованных лиц данного процесса на межрегиональном уровне позволит:

- создать условия, обеспечивающие сохранение и развитие каждой из систем традиционных художественных культур народов Южной и Восточной Сибири;

- повысить доступность, эффективность, качество, социальную востребованность и расширить спектр услуг в сфере традиционной художественной культуры;

- вовлечь население в активную социокультурную деятельность;

- обеспечить широкий доступ граждан из других регионов и стран к ценностям традиционной культуры народов Южной и Восточной Сибири;

- оказать поддержку в укреплении материально-технической базы учреждений, занимающихся сохранением и развитием традиционной художественной культуры на местах;

- укрепить потенциал традиционной художественной культуры через создание сетей.

Описание предлагаемых мероприятий и их эффективности.

- Проект предполагает комплексное обследование памятников традиционной художественной культуры алтайцев, тувинцев, бурят, эвенков, уникальных этнографических групп русского населения - старообрядцев и казаков в регионах Южной и Восточной Сибири методами экспедиционного исследования. Сложность и многокомпонентность традиционной художественной культуры предполагает, что эффективное и полноценное его описание возможно только при использовании электронной публикации. С её помощью возможно создание максимально полных произведений, основанных на сочетании самых разнообразных текстов, форм их представления, интересов пользователей и т. д. Поэтому будет создаваться мультимедийный электронный справочник, содержащий собранные экспедиционные материалы лучших образцов традиционной художественной культуры в виде описаний, фотографий, рисунков, видеоматериалов с возможностью поиска по представленным информационным объектам.

- Проведение межрегиональной научно-практической конференции по проблемам сохранения художественной культуры народов Южной и Восточной Сибири и обеспечение к ней доступа 
граждан из других регионов России и других стран. Материалы конференции будут опубликованы в виде традиционных сборников и в электронном варианте в интернете.

- Проведение научно-практической конференции по выработке проектных предложения по созданию заповедных зон традиционной художественной культуры в конкретных поселениях. Эти поселения будут объединяться в единую межрегиональную сеть художественно-культурных заповедников, чтобы в последующем стать крупными туристическими центрами Южной и Восточной Сибири.

- Организация фестивалей, концертов, праздников, выставок традиционной художественной культуры народов Южной и Восточной Сибири просветительской направленности в других регионах России.

- Создание информационного Web-портала, содержащего материалы, представленные в мультимедийном электронном справочнике и материалы конференции по проблемам сохранения художественной культуры народов Южной и Восточной Сибири, которые будут регулярно дополняться и обновляться.

- Создание научной, учебной, методической литературы, электронных информационных ресурсов по традиционной художественной культуре народов указанных регионов.

- Создание просветительских короткометражных видеофильмов по следам экспедиций на языках коренных народов Южной и Восточной Сибири и русском языке.

- Разработка методик обучения, передачи традиций художественной культуры, ориентированных в первую очередь, на детей и молодёжь.

В результате этой деятельности станет возможным:

- разработка долгосрочной концепции региональной и межрегиональной политики в сфере традиционной художественной культуры;

- координации на региональном и межрегиональном уровне программ культурных мероприятий

- объединение усилий государственных, общественных и частных структур регионального и межрегионального масштаба;

- развитие туристской инфраструктуры в регионах, прежде всего этнографического туризма.

- повышение конкурентной способности исполнителей и мастеров в реальном секторе экономики через гастрольно-концертную деятельность, продвижение на рынок туристических услуг разнообразных продуктов традиционной художественной культуры: фольклора, изделий народных художественных промыслов, бытовых традиций, обрядов, праздников;

- продвижение художественной культуры народов Южной и Восточной Сибири в других странах;

- представление лучших образцов традиционной художественной культуры народов Южной и Восточной Сибири в средствах массовой информации в регионах, стране и за рубежом;

Партнёрами в реализации проекта могут быть вузы и учреждения науки, министерства культуры Республик Алтай, Бурятия, Алтайского края, Министерство культуры и информационной политики Республики Тыва, Комитеты по культуре Забайкальского края, Иркутской области и др. В качестве партнёра может быть Международная Организация по народному творчеству (IOV) NGO UNESKO, коллективным членом которой является Восточно-Сибирский государственный институт культура (г. Улан-Удэ, Россия).

Участниками проектами могут стать республиканские Министерства образования и науки и областные комитеты по науке и образованию, местные учреждения культуры и образования, туристические фирмы регионов, которые могут выступить заказчиками отдельных мероприятий проекта.

По целям, задачам и направлениям деятельности проект совпадает с целевыми программами, направленными на сохранение нематериального культурного наследия народов отдельных регионов, а также Российской Федерации в целом. Таким образом, устойчивость проекта после его завершения обуславливается финансовой, научной, управленческо-организационной поддержкой на уровне Правительства Российской Федерации и соответствующих государственных и местных организаций в субъектах $[4 ; 5]$. 


\title{
Сиисок литературы
}

1. Черникова, В. Е. Диалог культур и цивилизаций как фактор обеспечения миропорядка и культурной целостности. - Текст : непосредственный // Вестник Северо-Кавказского федерального университета. Философские науки. - 2014. - № 3. - С. 143-147.

2. Гусев, В. Е. русская народная художественная культура: теоретические очерки. - Санкт-Петербург : СПбГИТМИК, 1993. - 110 с. - Текст : непосредственный.

3. Михайлова, Л. М. Народная художественная культура: детерминанты, тенденции, закономерности социодинамики. - Москва : [б. и.], 2012. - 246 с. - Текст : непосредственный.

4. Об объектах культурного наследия (памятниках истории и культуры) народов Российской Федерации : федеральный закон № 73-Ф3 от 25.06. 2002 г. - Текст : непосредственный // Российская газета. - 2002. 29 июня. - № 116/117.

5. Об утверждении Основ государственной культурной политики : указ Президента Российской Федерации № 808от 24 декабря 2014 г. - Текст : электронный // Консорциум «Кодекс», электронный фонд правовой и нормативно-технической информации : сайт. - URL: http://docs.cntd.ru/document/420242192 (дата обращения: 15.02.2019).

Nadezhda B. Dashieva, Dr. of Historical Sciences, Professor East-Siberian State Institute of Culture (Ulan-Ude) dashieva-n@yandex.ru

\section{CONSERVATION AND ADVANCEMENT OF SOUTH AND EAST SIBERIA'S PEOPLES' TRADITIONAL ARTISTIC CULTURE (A PROJECT NARRATIVE)}

\begin{abstract}
Keeping axiological and sense harmony in a system of traditional artistic culture of ethnic communities and strengthening of its capability to progress and growth are the key condition for reproduction of cultural diversity in the worldwide, All-Russian, and regional scales. The author outlines her own version of a project for conservation and advancement of traditional artistic culture of Turkic, Mongolian, and Slavic ethnoses settled rural areas of the today's South and East Siberia. Popularization of samples of people's artistic culture in intercultural network spaces is considered by the author as a recourse for social and economic growth of the less developed areas of Asian Russia.

Key words: traditional artistic culture, people's artistic culture, a multiethnic Russian area, difficulties in conservation of traditional artistic culture, an artistic and cultural reserve, Turkic peoples, Mongolian peoplsbl, Slavic peoples, Altaians, Tuvinians, Tofalars, Evenks, Russians.
\end{abstract}

УДК [248.153:281.93+338.482.22:2](470+571)

DOI: $10.32340 / 2414-9101-2019-2-15-18$

С. Ю. Житенёв, кандидат культурологии Российский научно-исследовательский институт культурного и природного наследия им. Д. С. Лихачёва (Москва, Россия) zhitenev@bk.ru

\section{ПРАВОСЛАВНОЕ ПАЛОМНИЧЕСТВО И РЕЛИГИОЗНЫЙ ТУРИЗМ В РОССИИ В НАЧАЛЕ ХХІ ВЕКА}

\footnotetext{
Аннотация. Охарактеризованы промежуточные итоги организационной, культурнопросветительной и редакционно-издательской деятельности Московского патриархата Русской Православной Церкви по возрождению традиций православного паломничества в современной России. Изложена авторская точка зрения на принципиальные различия в содержании терминов «паломничество» и «религиозный туризм», поддержанная Священным Синодом Русской Православной Церкви. Аргументирована необходимость сохранения за паломничеством особого правового статуса в российском законодательстве в целях предотвращения коммерциализации соответствующего сектора специализированных услуг; перечислены меры по законодательной поддержке православного паломничества на территории современной России.
} 